\title{
A prática docente e o dialogismo bakhtiniano: o ensino como um ato responsável
}

\author{
Teacher's practice and Bakhtinian dialogism: \\ teaching as a responsible act
}

\author{
Giselle Faur de Castro Catarino ${ }^{1}$. \\ Maria da Conceição de Almeida Barbosa-Lima ${ }^{1}$. \\ Glória Regina Pessôa Campello Queiroz ${ }^{1}$
}

\begin{abstract}
Resumo: Este trabalho tem como objetivo discutir o papel da dimensão dialógica no ensino, pensando a formação para cidadania como consequência do processo de construção do conhecimento. Para refletirmos sobre a Prática Docente de um professor de Física, discutiremos dois conceitos essenciais da teoria Bakhtiniana: o dialogismo e o ato. Ao final da construção do referencial teórico que esboce uma possível prática como ato dialógico e responsável, apresentaremos, a partir do discurso de um professor de Física, alguns episódios que enriqueçam esse referencial. Os dados aqui analisados foram coletados a partir de: e-mails trocados entre o professor e seus colegas de profissão, e o professor e um grupo de pesquisa da Universidade, e uma entrevista semiestruturada. Como uma das conclusões a que chegamos é que, no exercício - ato - de sua docência, o professor é capaz de se perceber como educador e de colocar - responder - sua prática em prol de seus objetivos.
\end{abstract}

Palavras-chave: Prática docente. Dialogismo. Ato. Ensino de física.

\begin{abstract}
This study carried out a survey of the main papers produced over the past decades about the understanding and thinking of the students in a measurement situation. It led to the development of a model-synthesis called Point and Set Paradigm. To develop research in this subject, a theoretical refinement is proposed to characterize the current paradigm into Categories of Conceptual Understandings which will contribute to a more thorough and qualitative understanding of students' conceptions regarding measurement.
\end{abstract}

Keywords: Teaching practice. Dialogism. Act. Physics teaching.

\footnotetext{
${ }^{1}$ Departamento de Física Aplicada e Termodinâmica, Instituto de Física, Universidade do Estado do Rio de Janeiro (UERJ), Rua São Francisco Xavier, 524, 3. andar, CEP 2550-900, Rio de Janeiro, RJ, Brasil. E-mail: <gisellefaur@gmail.com>
} 


\section{Introdução}

Ao analisar o currículo de Física de Ensino Médio, é notória a forte presença do paradigma newtoniano, favorecendo uma visão mecanicista do mundo em que vivemos, apesar das tentativas existentes de romper com essa lógica, como, por exemplo, a recente publicação dos currículos mínimos para o Ensino Médio (RIO DE JANEIRO, 2012). Essa visão retrata a situação da Física desde a estabilização do paradigma newtoniano até o século XIX.

A vertente mecanicista, desde o século XVII, tem sido dominante para o entendimento não só da natureza, mas, também, da sociedade e das organizações. O racionalismo mecanicista marcou profundamente o pensamento científico e concebeu uma realidade objetiva, delineada a partir de leis físicas e matemáticas. Como aponta Tôrres (2005), as leis de Newton tornaram legítimo o mecanicismo e validaram suas implicações: linearidade, monocausalidade, determinismo, reducionismo e imediatismo.

A revolução científica do início do século XX, gerada pela mecânica estatística, mecânica quântica e relatividade, levou o paradigma newtoniano a entrar em crise. Entretanto, nenhuma dessas revoluções abalou a mecânica de Newton que, na maioria dos currículos de Física de nível Médio, continua a ser a base sobre a qual se constrói a Física.

Hoje, com os desdobramentos das revoluções científicas e culturais, podemos ver um novo mundo, um mundo de sistemas complexos, regido por leis não redutíveis de maneira trivial às leis da mecânica. A complexidade deste mundo gera novas formas de pensar as relações entre simples e complexo e construir o conhecimento.

Diante desse novo mundo, complexo, pensamos ser imprescindível discutir o papel do professor de Ciências, mais particularmente o de Física, no atual sistema educacional, e suas implicações para a sociedade. É a partir da constatação de que precisamos repensar o atual panorama do Ensino de Física que vamos pensar a prática docente como "ato responsável".

Ao final, apresentaremos episódios de um docente que exerce sua prática a partir das tensões que se apresentam em seu desenvolvimento profissional: a tensão que surge da falta de parceiros dentro da escola para construir um trabalho inovador que dê espaço e voz aos alunos; a tensão política e ideológica no que diz respeito à implementação de sua prática na escola; além da tensão que vive na escola sobre a qualidade da educação, uma vez que se empenha, apesar das dificuldades, para construir uma educação de qualidade, sob sua perspectiva, enquanto questiona a postura de alguns colegas que não se comprometem com a escola e seus alunos.

\section{A prática docente como “ato responsável”}

É importante dizer quem foi Mikhail Bakhtin.

Apesar de sua vida conturbada por questões pessoais e políticas, Mikhail Bakhtin nos legou uma das obras mais importantes do século XX. A densidade de seu pensamento e de toda a sua obra permite várias abordagens em diversas áreas de conhecimento, não havendo a possibilidade de encaixá-lo em uma chave classificatória simples (FARACO, 2001 apud TEIXEIRA, 2006, p. 229), apesar das tentativas, apontadas por Teixeira de enquadrá-lo em esquemas predeterminados.

Todo o arcabouço teórico-reflexivo da teoria bakhtiniana (BRAIT, 2005) aparece no estudo de questões da linguagem em diversas áreas, como na Linguística e Literatura e em 
campos transdisciplinares como: a educação, a pesquisa, a história, a antropologia, a psicologia, entre outras.

Para relacionar a prática docente e a teoria de Bakhtin, é preciso lançar mão de conceitos que sirvam de ponte entre o aparato teórico e o mundo prático onde se desloca o professor-intelectual. Apoiamo-nos em Giroux (1997) para pensar os professores como intelectuais transformadores, ou seja, para pensar a atividade docente como forma de trabalho intelectual que envolve uma forma de pensamento reflexiva voltada para seu fazer cotidiano. A perspectiva é de que todo professor se baseia em convicções ideológicas e práticas para o desenvolvimento de sua atividade docente, e que, consequentemente, produzem e legitimam interesses políticos, econômicos e sociais variados por meio de suas práticas (GIROUX, 1997).

Para iniciarmos a discussão, é inevitável instigar a reflexão acerca da ação dialógica a partir de um "ato responsável" (não indiferente e responsivo, ou seja, uma compreensão que responde, uma escuta que fala, não necessariamente imediata e diretamente), como primeiro aponta Bakhtin em Para uma filosofia do ato responsável (2010). É nesta obra que Bakhtin realiza uma profunda reflexão filosófica sobre o ato. Revela, então, a existência de dois mundos: o mundo da cultura e o mundo da vida. O mundo da cultura é o mundo no qual "se objetiva o ato da atividade de cada um" (BAKHTIN, 2010, p. 43), enquanto no mundo da vida - historicidade viva -, atos únicos e irrepetíveis são realizados por seres históricos. Na visão do pensador russo, estes dois mundos se confrontam e são impenetráveis entre si devido à unicidade irrepetível da vida, realmente vivida e experimentada: “[...] somente o evento singular do existir no seu efetuar-se pode constituir essa unidade única; tudo o que é teórico ou estético deve ser determinado como momento do evento singular do existir, embora não mais, é claro, em termos teóricos ou estéticos" (BAKHTIN, 2010, p. 43).

Assim, segundo Sobral (2008), o ato "responsável" de Bakhtin trata do agir humano no mundo concreto, retratando as maneiras pelas quais os indivíduos o concebem simbolicamente, por meio da linguagem: “O empreendimento bakhtiniano sobre essa questão consiste em tentar mostrar como generalizar acerca das singularidades que são os atos sem perder de vista sua singularidade nem a generalidade!” (SOBRAL, 2008, p. 224). Ou seja, o ato, como aspecto geral, surge como conceito, no mundo da cultura, enquanto os atos concretos são particulares e singulares, permeados pelos tons emotivo-volitivo - perspectiva axiológica - no mundo da vida. Em outro trabalho, Sobral (2009) aponta ainda que há sempre duas perspectivas envolvidas nas pesquisas sobre os atos: a dos atos concretos - irrepetíveis; e a dos atos enquanto atividade - o que há em comum em vários atos, ou seja, repetível. Isso pode gerar dois problemas: como não apagar a especificidade dos atos e como não perder, nessa especificidade, o que há em comum nos vários atos? Sobral (2008, p. 224) propõe, ainda, a existência de dois planos, que, segundo ele, são inter-relacionados, um plano da generalidade e um da particularidade: "ele [Bakhtin] distingue entre o conteúdo do ato, isto é, aquilo que o ato produz ao ser realizado, ou seu produto, e o processo do ato, ou seja, as operações que o sujeito realiza para produzir o ato".

$\mathrm{Na}$ Educação, sobre generalidade - mundo da cultura - e particularidade - mundo da vida -, poderíamos pensar que as teorias desenvolvidas acerca da prática docente seriam uma maneira de generalizar aspectos dessa prática, encontrar alguma regularidade - valorização de uma cultura comum - e teorizar sobre ela. Entretanto, uma teoria nunca dará conta de "ser" a própria prática, pois cada prática é singular, é única e nem pode ser reproduzível. Dessa maneira, o discurso de um professor sobre sua prática, por exemplo, pode carregar um tom de 
generalidade, tentar externar o desejo de realização de uma determinada prática, enquanto sua prática em sala de aula sempre será única e, nem sempre, acompanhará ou será completamente fiel ao discurso sobre ela. Concordando com Tardif e Lessard (2005, p. 46), a docência se apresenta como "um trabalho fortemente contextualizado, concreto, posicionado (SCHÖN, 1983), marcado principalmente pelas contingências situacionais". Além disso, nem sempre, os objetivos traçados pelos professores para justificar seus atos correspondem às condições de ação: "os atores não fazem sempre o que dizem fazer e não dizem necessariamente, inclusive a si mesmos, o que fazem efetivamente" (TARDIF, 2002, p. 204).

Segundo Ponzio (2010), Bakhtin pensa o mundo da cultura a partir de um ponto de vista teórico. Nele, o sentido do ato perde o caráter de evento único, vivido, e assume "um valor genérico, um significado abstrato" (PONZIO, 2010, p. 16). Para exemplificar relações no mundo da cultura, aponta, ainda: as relações sociais, culturais, reconhecidas oficialmente, relações entre identidades do gênero, entre pertencimentos, entre diferenças que são indiferentes à singularidade, ou seja, relações onde a alteridade é apagada. Podemos, no caso de nossa pesquisa, tratar O Professor a partir de uma identidade coletiva, como sujeito do mundo da cultura, enquanto, no mundo da vida, cada professor possui uma identidade individual, uma singularidade que torna sua prática única e insubstituível.

Voltando a Bakhtin, os atos são irrepetíveis e únicos, mas guardam elementos comuns com outros atos e, por isso, podem fazer parte de um ato como "categoria englobante" (SOBRAL, 2008). Não é possível, então, apagar a especificidade dos atos, marcando apenas o que há em comum, ou seja, não é possível que a teoria apague a vida concreta (plano da particularidade) e que a prática concreta apague a teoria (plano da generalidade). Da mesma maneira, é possível compreender a existência da teoria, da abstração, mas não é possível tornar, esse mundo, nosso mundo real. Assim, para Bakhtin (1993, p. 1 apud SOBRAL, 2008, p. 226), deve-se evitar a separação entre "o conteúdo ou sentido de um dado ato/atividade e a concretude histórica do ser desse ato/atividade, a experiência atual e uni-ocorrente dele".

A leitura de Young (2011), ao refletir sobre o futuro da educação em uma sociedade do conhecimento, nos leva a pensar as relações entre a teoria e a prática em sala de aula. Segundo este autor, uma das tarefas mais complexas na interação com o conhecimento é não confundir o "lugar da experiência" com o "objeto do pensamento". Existe uma diferença entre essas duas dimensões que precisa ser captada pelos alunos e marcada pelos professores. Entretanto, tal questão não é simples, uma vez que os conceitos cotidianos são captados de forma inconsciente e adquiridos pela experiência, em contextos bem particulares. Por outro lado, tais conceitos estão associados, também, a abstrações teóricas. Como separar essas duas dimensões? Sobral (2008, p. 226) conclui que compreender um ato é compreender o todo do ato, "sua dialética produto -processo, seu caráter situado, isto é, de ação humana que ocorre num hic et nunc, aqui e agora".

Compreender o "todo do ato" nos faz pensar em uma ponte entre o mundo da cultura e o mundo da vida. É esse o papel pedagógico, apontado por Young (2011): é preciso que o professor crie uma ponte que leve o aluno do conceito cotidiano para o conceito teórico. É necessário que o professor intelectual - mediador, herdeiro, crítico e intérprete da cultura, como caracterizado já anteriormente - assuma seu papel de sujeito e estabeleça os elos entre os saberes e interpretações que explicam o mundo e o contexto no qual os alunos estão imersos. A existência dessa ponte - travessia do mundo da cultura ao mundo da vida - nos permite analisar, então, a construção do conhecimento e a prática docente à luz da teoria bakhtiniana do ato. 
Com efeito, o aluno precisa dessa ponte para compreender as dimensões dos conceitos. Por outro lado, o professor intelectual, no universo de sua atividade docente, se depara com mundos, pontes e travessias, se desloca no espaço-tempo que pode ser articulado analogamente aos mundos de Bakhtin. Esse universo da atividade docente compreende o mundo do agir, das relações, da sala de aula (mundo da vida) e o mundo teórico e organizado, do pensar, do conceituar (mundo bakhtiniano da cultura). A ponte entre os dois mundos, lugar de travessias, idas e vindas entre a teoria e a prática, é o território privilegiado do professor intelectual, construído e constituído por tensões que se apresentam nos atos responsáveis.

Ainda sobre esses atos, Bakhtin (2010, p. 43) os caracteriza como atos que devem encontrar unidade de responsabilidade em duas direções: “seja em relação ao seu conteúdo (responsabilidade especial), seja em relação ao seu existir (responsabilidade moral)". É na transição do mundo da cultura/teórico para o mundo da vida/prático que o dever surge, e esse momento é único: "é sempre um ato individual, que não afeta em nada a validade teórica objetiva do juízo - é um ato que é avaliável e imputável no contexto único da vida real única de um sujeito" (BAKHTIN, 2010, p. 46).

Que vida real responsável é essa? Nela, o ato ou a ação realmente se desenvolve, nela surge a unicidade irrepetível da vida realmente vivida e experimentada. Dessa maneira, a filosofia do ser-evento, único, "não pode ser abstraída do ato-ação real, único e de seu autor - aquele que está pensando teoricamente, contemplando esteticamente e agindo eticamente" (SAMPAIO, 2009, p. 45). Sobre o ato responsável, Bakhtin (2010, p. 94) nos diz:

Não é o conteúdo da obrigação escrita que me obriga, mas a minha assinatura colocada no final, o fato de eu ter, uma vez, reconhecido e subscrito tal obrigação. E, no momento da assinatura, não é o conteúdo deste ato que me obrigou a assinar, já que tal conteúdo sozinho não poderia me forçar ao ato - a assinatura-reconhecimento, mas podia somente em correlação com a minha decisão de assumir a obrigação - executando o ato da assinatura-reconhecimento; e mesmo neste ato o aspecto conteudístico não era mais que um momento, e o que foi decisivo foi o reconhecimento que efetivamente ocorreu, a afirmação - o ato responsável, etc.

O termo assinatura significa postura axiológica em relação ao ato. O sujeito só toma uma decisão por ser um sujeito moral dotado de liberdade: "Posso estar de acordo com uma proposição, mas dizer que, por isso mesmo, ela se torna uma norma que controla a minha ação significa passar por cima do problema fundamental" (BAKHTIN, 2010 apud FARACO, 2010, p. 152). Faraco (2010) compreende aí uma crítica ao teoricismo, à valorização da teoria sobre a prática, à pretensão da teoria de ser universal.

Nesse sentido, Bakhtin se mostra um crítico do racionalismo (FARACO, 2009, p. 20), do pensamento universal contrário ao singular, da lei geral ao invés do evento, do objetivo que se contrapõe ao subjetivo: "incomoda-lhe a ideia de sistema em que não há espaço para o individual, o singular, o irrepetível, o evêntico”.

É por isso que a atividade docente, diante do que dissemos acima, é marcada pela eclosão desses eventos irrepetíveis. Somente o que é constante não faz a docência intelectual, é necessário o irrepetível, o evêntico, o único. É o que a faz dinâmica, não estagnada, pois é nesse 
sentido que o professor, também sujeito da ação, passa a se perceber único e a se posicionar, assumindo, então, a responsabilidade: se eu sou insubstituível, devo realizar minha unicidade (BAKHTIN, 2010). Cada sujeito ocupa um lugar irrepetível e insubstituível no mundo e, por isso, na perspectiva de Bakhtin, o sujeito deve ser responsável por seus atos e ter obrigação ética com relação ao outro.

Ser - existir - na vida significa, então, agir, enunciar. Só eu posso realizar minha singularidade. Isso não quer dizer que o sujeito está sozinho no mundo: sempre existe o outro centro axiológico - o outro - que participa do processo dialógico, que baliza o agir responsável do sujeito e para quem o sujeito se dirige.

\section{A busca pelo outro: dialogismo e alteridade}

Diante de nossa proposta de pensar a atividade docente como um trânsito em uma ponte, que precisamos discutir a relação eu/outro. O professor age pensando no outro, vários "outros". Cada outro é constituído pelo seu centro de valores - axiológicos - que se contrapõem e geram a realização de atos concretos. Não podemos deixar de apontar que as tensões do professor se baseiam também nos embates com o outro.

Fica claro que a reflexão filosófica de Bakhtin sobre o ato, sucintamente esboçada no item anterior, é sustentada pela noção de alteridade (FARACO, 2009), que se estabelece na relação de "um eu-para-mim, o outro-para-mim e o eu-para-o-outro" (SAMPAIO, 2009).

Como conceitua Amorim (2004) a definição de alteridade está relacionada ao efeito de uma distância: compreender um fato social implica

[...] apreendê-lo totalmente, isto é, de fora, tal como uma coisa, mas da qual somos parte integrante. [...] De um lado, participamos subjetivamente de todas as sociedades posto que elas são humanas. Nós poderíamos ter nascido ali e podemos então procurar compreendê-las como se nelas tivéssemos nascido. Por outro lado, cada sociedade está virtualmente dividida ao infinito por processos em que, num dado momento, uma parte pode tornar objeto de análise para outra. (AMORIM, 2004, p. 68-69)

O conceito de alteridade que se apresenta em Bakhtin tem extrema importância para nossa pesquisa e para minha postura do investigador diante do outro/sujeito: "O próprio fato de que todo objeto de pesquisa é um objeto construído e não imediatamente dado, já implica um trabalho de negociação com os graus de alteridade que podem suportar a pesquisa e o pesquisador" (AMORIM, 2004, p. 29-30). Por isso, além de nos enchermos da noção de alteridade para criarmos uma relação pesquisador-sujeito para nossa pesquisa, tal noção nos ajudará a pensar a alteridade do professor-aluno, professor-escola, professor-sociedade.

Ao discutir alteridade, Amorim (2004), que fala do tema na perspectiva da pesquisa, conclui que é preciso valorizar a presença do outro - sujeito - que fala e produz ideias. Ou seja, não é possível ignorar a existência desses outros - aluno, escola, sociedade - no enunciado do professor. Dessa maneira, o outro se constitui como um objeto para o professor intelectual construir sua prática e suas estratégias de ensino, pesquisa e ação num contexto filosófico e político. 
A alteridade está no descobrir-se outro ou no descobrir o outro em mim. Essa visão de alteridade permite que as marcas do outro apareçam na atividade docente, de maneira a transformá-la e obrigá-la a "falar" de outro modo (AMORIM, 2004), com outra linguagem, outros caminhos. Nesse caminho, a alteridade deixa de ser um simples conceito teórico, instala-se no processo contínuo de tornar-se professor, gerando tensões, crises, indagações. São essas crises e indagações que criam a verdadeira dinâmica da docência e da pesquisa, conduzindo-as aos seus desfechos, sempre provisórios, inacabados.

É nesse sentido que surge a necessidade de se discutir o dialogismo bakhtiniano: eu só existo diante do outro, o outro me constitui, me modifica, me transforma. Como ressalta Goulart (2010, p. 56), “o diálogo é o princípio básico da constituição da arquitetônica bakhtiniana”. É a partir do dialogismo que se constitui o sujeito dentro da sociedade, sujeito em permanente construção e que só existe na presença de elementos históricos, sociais e outros, que fazem parte de um contexto complexo interativo (BAKHTIN, 2011), ou seja, "o dialogismo bakhtiniano se fundamenta na negação da possibilidade de conhecer o sujeito fora do discurso que ele produz" (DAHLET, 1997 apud TEIXEIRA, 2006, p. 229). Esse ponto é essencial para a discussão: o dialogismo é a base do processo de construção do sujeito e do conhecimento; "é uma categoria essencial da natureza da linguagem" (TEZZA, 2003, p. 232).

$\mathrm{O}$ dialogismo tem como característica principal "conceber a unidade do mundo nas múltiplas vozes que participam do diálogo da vida” (SOUZA, 2001, p. 104). É notória a importância dessa análise na sala de aula e no discurso filosófico-político-pedagógico do professor: são as múltiplas vozes que aparecem na sala de aula que possibilitarão, por meio da interação dialógica, o embate entre os opostos, o aprofundamento do processo de construção do conhecimento. As múltiplas vozes significam múltiplos pontos de vista, múltiplas culturas, múltiplas possibilidades. Dessa maneira, por meio de uma ponte que ligue o mundo da cultura ao mundo da vida, podemos pensar na postura do professor diante de seu público, seus objetivos, seus ideais de educação.

Entendamos, para isso, o primeiro conceito-chave da teoria de Bakhtin que baseia as relações: a unidade de comunicação verbal. No que diz respeito ao enunciado, Goulart (2010, p. 53), ao defender a ideia de que enunciar é argumentar, revela que "enunciar é agir sobre o outro, isto é, enunciar extrapola a ideia de compreender e responder enunciados". Dessa maneira, toda enunciação é um diálogo e faz parte de um processo de comunicação ininterrupto: "Não há enunciado isolado, todo enunciado pressupõe aqueles que o antecederam e todos os que o sucederão: um enunciado é apenas um elo de uma cadeia, só podendo ser compreendido no interior dessa cadeia" (SOUZA, 2001, p. 99), ou seja, nenhum texto se origina do nada, mas sempre representa uma resposta a outros textos ou a outro universo de referência com que dialoga. Além disso, o enunciado é composto pelo extraverbal - constituinte necessário de sua estrutura semântica (AMORIM, 2006, p. 107).

A prática do professor como discurso deve ser um elo na cadeia do processo de ensino e aprendizagem. É preciso que a voz do aluno tenha lugar em sala de aula, que ele se posicione. Além disso, a docência como singularidade deve pretender dar conta de levar os alunos à abstração, ao mundo da cultura, para que eles também, a partir da vida concreta, consigam elaborar suas próprias explicações, suas próprias teorias a respeito do mundo que os cerca. 


\section{Um exemplo}

Vamos trazer aqui episódios da análise do discurso de um professor de Física sobre sua prática. Nosso sujeito é licenciado em Física e dedica-se ao magistério na rede estadual de educação e à mediação em um Museu de Ciência e Tecnologia. Além disso, é mestre em Ensino de Ciências por uma instituição federal do Rio de Janeiro.

Este professor se coloca como um professor contra-hegemônico que não deixa de lutar pelo direito dos alunos e da escola pública. Nesse sentido, alguns atritos, que analisaremos a seguir, são apenas parte dos embates nos quais Francisco foi protagonista. É nesta perspectiva que o referencial teórico estudado nos dará base para pensar uma prática que busca transgredir essa lógica atual do sistema educacional, uma prática que escuta, responde e se posiciona.

Preocupado com a formação social e política de seus alunos, o professor tem por lema: Por uma escola pública de qualidade e digna, para todos. Tal slogan é escrito por ele em todos os seus e-mails. Os dados aqui analisados foram coletados a partir de: e-mails trocados entre o professor e seus colegas de profissão, e o professor e um grupo de pesquisa da Universidade, e uma entrevista semiestruturada. Os enunciados de nosso sujeito foram organizados em três episódios - liderança, prática contra-hegemônica, professor-pesquisador.

\section{$1^{\circ}$ episódio: a liderança}

- E-mail enviado pelo professor aos seus colegas da Escola no dia 10 de fevereiro de 2011. O contexto desta primeira mensagem é o início do ano letivo de 2011.

Este e-mail inicialmente se dirige aos colegas de área, mas é claro que está aberto para os demais que se interessarem em trabalhar em conjunto com os coleguinhas da área das Ciências da Natureza [...] Aos coleguinhas de L. Portuguesa as ferramentas trabalhadas por vocês serão extremamente úteis, vamos fazer dos nossos monstrinhos os protagonistas do processo de Ensino e Aprendizagem. [...] Eu Prof. de Física, gostaria muito de poder trabalhar com os demais colegas, para tal fiz uma pequena consulta às competências e habilidades das disciplinas: Física, Química e Biologia. Fiquei animado ao perceber uma possibilidade para podermos unir nossos esforços em prol de um Ensino Público de Qualidade, como todos já devem ter percebido no Jardim de Inverno, uma mesa improvisada onde estão os Terrários (micro ecossistema fechado, onde há apenas troca de energia) construídos com algumas turmas do $1^{\circ}$ ano de 2010, utilizamos duas garrafas PET, brita, areia, terra adubada, água e fita adesiva. Mas enfim, o que isso tem a ver com os colegas de área? - Biologia: no segundo item do $1^{\circ}$ Bimestre; Química: no segundo item do $1^{\circ}$ Bimestre; Física: $1^{\circ}$ Bimestre. Enfim dentro desta maluquice pretendo realizar duas oficinas, a primeira é claro de construção e discussão do Terrário e uma oficina de sorvete (galera de Química vamos usar salmoura para congelar o sorvete, e galerinha de Biologia para que o sorvete não vire uma pedra de gelo as gorduras são fundamentais) com os nossos monstrinhos. POR UM ENSINO PÚBLICO DE QUALIDADE. 
Neste e-mail, o professor tenta assumir um papel de liderança, no que transparece sua preocupação com o engajamento dos colegas em um trabalho coletivo, procurando motivá-los, convidando-os a observar as produções dos alunos, entre as quais se incluem produtos de oficinas pedagógicas - estratégias que valorizam o aluno e seu papel de protagonista, engajando-o no processo de ensino-aprendizagem - de caráter experimental e voltadas para a divulgação da ciência. Dessa maneira, não apenas teoriza possibilidades de integração das diversas disciplinas, mas apresenta como estas possibilidades podem se tornar atividades reais na escola. As estratégias que o professor coloca se tornaram parte do seu repertório híbrido, construído na fronteira entre as duas culturas: em função tanto da sua formação inicial, como da sua ação em um museu de ciência e tecnologia. Notamos, ainda, que, para se mostrar aberto ao trabalho com outras áreas de conhecimento, nosso sujeito buscou, de alguma maneira, romper as barreiras disciplinares, estudando como outras disciplinas podem trabalhar em conjunto com a Física por meio da perspectiva inter e transdisciplinar.

É possível perceber que Francisco constrói e compartilha novos sentidos possíveis para os itens curriculares disciplinares fixados no currículo escolar: conteúdos abstratos que participam do mundo da cultura. A partir do discurso hegemônico, nosso sujeito cria novas possibilidades de interação entre as áreas de conhecimento, e convida seus colegas a participarem desta nova perspectiva a ser posta em prática: mundo da vida.

A busca pelo trabalho coletivo representa, ainda, uma perspectiva de identidade docente baseada, também, no saber da socialização e na interação com o outro.

Não podemos deixar de ressaltar os sentidos que o termo "coleguinhas" pode ter e gerar na leitura dos professores destinatários: pode haver um entendimento de carinho como tentativa de aproximação, mas também de deboche, podendo gerar um afastamento antes mesmo do primeiro contato. Como aponta Bakhtin (2011), as mesmas palavras podem significar coisas muito diferentes dependendo da entonação individual com que são enunciadas em um contexto específico: "a entonação é o som que o valor faz" (CLARK; HOLQUIST, 1998, p. 37). Para o próprio Bakhtin, a entonação expressiva é um traço que constitui o enunciado: "Um dos meios de expressão da relação emocionalmente valorativa do falante com o objeto da sua fala é a entonação expressiva que soa nitidamente na execução oral" (BAKHTIN, 2011, p. 290). Em outra obra, Bakhtin chama atenção para o fato de que: "Na realidade, não são palavras o que pronunciamos ou escutamos, mas verdades ou mentiras, coisas boas ou más, importantes ou triviais, agradáveis ou desagradáveis, etc. A palavra está sempre carregada de um conteúdo ou de um sentido ideológico ou vivencial" (BAKHTIN, 2006, p. 98-99. Grifo do autor).

\section{$2^{\circ}$ episódio: a prática contra-hegemônica}

- E-mail enviado por Francisco dia 2 de abril, com fotos do evento organizado por ele na escola:

Encaminho as fotos do $2^{\circ}$ Museu vai à Escola (o $1^{\circ}$ foi o evento $1^{\circ}$ Fast Ice Cream), realizado no dia 31 de março de 2011 no Colégio Estadual. Realizamos duas atividades simultaneamente (além é claro da minha aula para as minhas turmas): Cozinhando com a Química: Bolo de Chocolate de Caneca no Micro-ondas e Fala Primeiro: Quiz Astro- 
nômico. Agradeço imensamente a colaboração, participação e carinho dos estagiários. Agradeço a Coordenação de Educação em Ciências do Museu por nos proporcionar não apenas o convívio com colegas de trabalho tão especiais, mas para além disso amigos e amantes desta profissão (Professor-Mediador). Dizem os boatos que tiveram alunos que fizeram as duas oficinas em casa para os familiares... construíram terrários... entre outras atividades que já trabalhamos no Colégio.

Fica evidente a tentativa de nosso sujeito de fazer com que a escola seja um ambiente agradável para os alunos e com que o conhecimento a ser construído faça sentido na vida dos estudantes. É preciso dizer que nosso sujeito, em seu discurso durante a entrevista, critica a descrença dos outros professores quanto às reais possibilidades de um desempenho satisfatório dos alunos. Revela-se, ainda, um professor que tenta superar as dificuldades de um trabalho solitário na escola em que atua, e que diversos aspectos influenciam sua atividade docente, como: o meio de trabalho, os alunos, a estrutura escolar precária, a direção da escola, entre outros. Para fazer com que a escola seja um ambiente agradável, se utiliza de oficinas pedagógicas para trabalhar conteúdos, não só de Física como, também, de outras disciplinas. O desenvolvimento das várias oficinas pedagógicas - Cozinhando com a Química: Bolo de Chocolate de Caneca no aparelho de Micro-ondas e Fala Primeiro: Quiz Astronômico - na prática de Francisco caracteriza uma motivação inicial para a implementação de um projeto pedagógico na escola, na busca de uma ponte entre a educação formal e não formal. Isso nos revela a prática híbrida de nosso sujeito, construída a partir de sua formação diferenciada: Universidade/Museu/Escola.

Entre as várias fotos que ele enviou, selecionamos duas do Quiz na Escola (Figura 1).

Percebemos, pelas fotos e pelo enunciado do professor, que os alunos se mostraram muito curiosos e participativos nas atividades realizadas. Podemos dizer que as estratégias de Francisco buscam o respeito à curiosidade do educando, seu gosto estético, sua inquietude, sua linguagem (FREIRE, 1996). É notória, então, a característica dialógica de nosso sujeito não

Figura 1. Quiz na Escola.
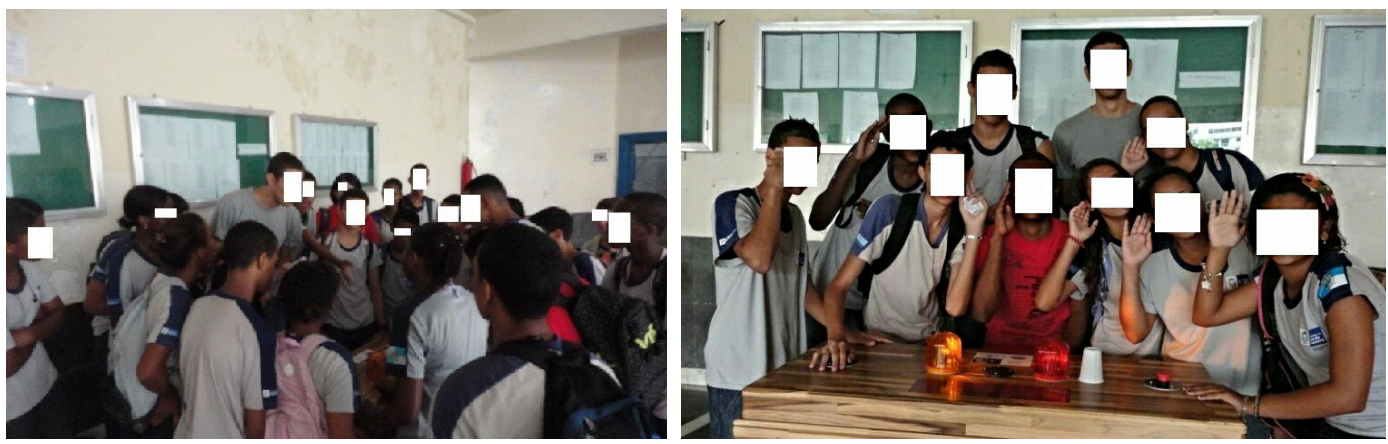

Fonte: Fotos capturadas pelo professor da turma durante a atividade na Escola. 
somente com os alunos que participam ativamente das atividades, mas, também, com os professores, compartilhando o processo e os resultados de suas estratégias, e com outros profissionais da educação - estagiários da universidade e do museu. Este diálogo revela a busca pela parceria entre educação formal - Universidade/Escola - e educação não formal - Escola/Museu, já construída em sua identidade docente, que podemos chamar de híbrida. Tal hibridismo, apesar de sugerir certa homogeneidade, é resultado de tensão entre as culturas formal e não formal. Notamos isso ao analisarmos o discurso do professor Francisco, na segunda entrevista, sobre como ele caracterizaria sua própria identidade profissional:

Sei lá. Um estranho que... já me perguntaram qual era disciplina que eu dava de verdade. Porque a professora estava na dúvida se en era professor de física realmente. Ela perguntou, professora que já conheço, trabalho com ela. Ela: Vem cá afinal de contas você é professor de que? De Biologia, de Artes. Porque não tenho uma identidade de professor de física A minha ideia é trabalhar um pouco de tudo também. Trazer tudo que puder para ajudar em sala de aula. (Professor Francisco)

Ele não identifica, no momento da enunciação, a especificidade da sua área de formação em sua própria identidade. Pelo contrário, ele percebe sua identidade a partir das necessidades dos alunos para compreenderem o conhecimento abordado por ele.

Podemos apontar, ainda, a dimensão política atrelada à identidade de Francisco, a partir do contexto das atividades propostas no e-mail. Para apreender o compromisso político-social que o professor possui em relação a seus alunos, é importante dizer que professores da rede pública estadual estavam em paralisação no dia da realização das oficinas. Francisco recebeu crítica de professores por ter trabalhado com seus alunos neste dia, inclusive, uma professora enviou um e-mail parabenizando o entusiasmo do professor com as atividades, mas criticando a data da realização como falta de respeito ao movimento de paralisação, apesar de ela mesmo não ter comparecido ao ato.

- Resposta de Francisco ao e-mail da professora:

[...] encaminho o e-mail em resposta a questão. Teve aula no turno da manhã, com oficinas de bolo de chocolate (através da atividade Cozinhando com a Química) e Quiz Astronômico (uma parceria entre o Instituto de Física da Universidade, Museu e CE) e aula de Física com o autor deste pequeno grande e-mail. [...] entendo perfeitamente a posição da maioria dos professores, mas eu enquanto professor-pesquisador [...] já percebi o quão inútil são estas paralisações, nós estamos apenas reforçando a política da não aula [...] eu apenas acho que isso não deve ser uma coisa boa, apenas acho! Lugar de aluno é na escola, e se for necessário sair da escola para alguma coisa, façamos um aulão público na frente do palácio Guanabara [...] Temos que resgatar a cultura da boa escola, reconstruir essa identidade de escola que nos foi retirada, lugar de criança é na escola e a escola tem que trazer benefícios e o que eu mais prezo em meio a tudo isso é a felicidade... será que não temos como 
sermos felizes? Ou mesmo fazermos nossos alunos felizes dentro da escola? Entendo perfeitamente que merecemos melhores salários, mas não é por isso que serei infeliz e farei meu aluno infeliz, sejamos felizes, porque se estivermos todos juntos, aí sim, acredito numa real mudança... [...] POR UMA ESCOLA PÚBLICA DE QUALIDADE, para todos”.

Notamos, inicialmente, que este e-mail, não somente pelo tamanho, mas, também, pelo conteúdo escrito, é uma resposta de natureza social, de um professor que luta pelo que considera melhor para seus alunos a professores e servidores. Para ele, "lugar de aluno é na escola", uma escola que valorize seus alunos, que busque formar seus alunos de maneira prazerosa e feliz. Por isso, Francisco acredita que cancelar as aulas não contribui para a formação de seus alunos. Isso não quer dizer que ele seja contra o posicionamento dos profissionais da educação em relação à política atual, ao plano de carreira dos professores, mas, para ele, tais paralisações pioram a situação de baixa aprendizagem de seus alunos, que estão em primeiro lugar. $\mathrm{Ou}$ seja, ele não rejeita uma postura política em que a comunidade de professores reivindique seus direitos, apenas não considera pertinente tirar os alunos da escola, ou melhor, tirar os alunos de uma situação de ensino e aprendizagem. Isso fica bastante claro em seu discurso quando aponta uma sugestão para uma reivindicação: "Lugar de aluno é na escola, e se for necessário sair da escola para alguma coisa, façamos um aulão público na frente do palácio Guanabara”. O importante para o nosso sujeito é que o aluno - protagonista - não perca a possibilidade de se relacionar com o conhecimento em todas as situações.

Não podemos deixar de ressaltar a identidade assumida pelo próprio professor quando se diz um professor-pesquisador. É claro que ser um pesquisador não é simples, mas nosso sujeito vai mostrar que, além de inovar a própria prática e a aprendizagem dos alunos através de oficinas, acompanhando esse processo com uma pesquisa acadêmica em seu mestrado, vai buscar, em parcerias com a universidade, legitimar seu conhecimento e os resultados de suas estratégias - validando o saber da ação pedagógica. Tal fato revela uma maturidade teórica e prática de um professor que, como mostrará o próximo episódio, quer que seus colegas - professores e pesquisadores - percebam que é possível fazer diferente/diferença.

\section{$3^{\circ}$ episódio: o professor-pesquisador-coformador de novos professores}

- No dia 04 de abril, Francisco conversa com a Universidade, mais especificamente com licenciandos em estágio supervisionado e bolsistas de extensão e iniciação científica de um grupo de pesquisa com quem vem desenvolvendo seu projeto pedagógico na escola:

Fala Crianças, to querendo escrever um artigo sobre a importância do uso de oficinas pedagógicas e a nossa interação na formação inicial de vocês, para tal acho que seria interessante que cada um escreva sobre as atividades que participaram... O que gostaram o que foi diferente, o que não foi legal, as vantagens de se utilizar desta metodologia... Quero mostrar para o Brasil que essa metodologia tem vantagens para todos os níveis, para a formação inicial e continuada do professor, por existir troca entre a universidade e a escola via estagiários, ou mesmo entre o 
museu e a escola... colabora para uma formação inicial que valorize a participação ativa de nossos alunos em atividades coletivas como nossas oficinas.... Podemos também ressaltar as perturbações que este tipo de estratégia causa no interior da escola [...] Enfim temos muita coisa para escrever, não sei se conseguiremos abordar tudo num artigo, mas vamos lá [...] POR UMA ESCOLA PÚBLICA DE QUALIDADE, para todos.

Para finalizar, ao mesmo tempo em que planeja e realiza atividades na escola, Francisco conversa com a Universidade e propõe que algumas de suas ideias se tornem artigos para serem apresentados a um público mais amplo, demonstrando que vê sentido no que faz e percebe as contribuições disso na e para a formação inicial dos licenciandos da Universidade onde se formou e com a qual mantém parceria. Tal discurso mostra a capacidade de um professor se tornar um pesquisador e analisar a própria prática de forma crítica: "No meu entender o que há de pesquisador no professor não é uma qualidade ou uma forma de ser ou de atuar que acrescente à de ensinar. Faz parte da natureza da prática docente a indagação, a busca, a pesquisa" (FREIRE, 1996, p. 29).

Além disso, seu desejo é compartilhar com os pares (o Brasil) os resultados alcançados com a luta teórica e prática para mudanças no atual quadro da Educação, apontando, novamente, a validade do saber da ação pedagógica. Seu desejo é tornar seu mundo da vida - seus atos irrepetíveis, sua vivência em sala de aula e fora dela -, ou aspectos dele, uma generalidade, um discurso com certa regularidade, e possibilitar o enriquecimento do mundo da cultura que diz respeito à comunidade dos professores de física de Ensino Médio.

\section{Considerações finais}

Pensamos que o professor deve assumir a responsabilidade em relação à sua prática. Ele é único e, portanto, precisa intervir efetivamente no processo de ensino e aprendizagem e ser capaz de estabelecer objetivos e prioridades e de definir as reais necessidades dos sujeitos.

Entendemos que a descontextualização e isolamento do ensino de Física em relação aos reais problemas vivenciados pelos estudantes são grandes desafios a serem superados por práticas realmente comprometidas. É preciso ultrapassar o panorama da educação científica que apresenta como majoritária a orientação propedêutica do ensino, em detrimento de outros âmbitos formativos importantes, tais como atitudes, valores, relações entre Ciência, Tecnologia e Sociedade.

A partir da análise dos episódios, podemos inferir que o professor Francisco visa à construção de um repertório que valoriza o experimento e o questionamento e o papel do aluno como protagonista durante a construção do seu conhecimento.

A valorização de uma postura dialógica em sala de aula nos permite dizer que Francisco se envolve em um movimento dinâmico e dialético entre o fazer (mundo da vida) e o pensar (mundo da cultura), refletindo criticamente sobre a própria prática. Dessa maneira, o ir e vir entre teoria/prática aparece em seu discurso sobre sua sala de aula. É exatamente nesse sentido que acreditamos que Francisco, no exercício - ato - de sua docência, é capaz de se perceber como educador e de colocar - responder-, de forma consciente, sua prática em prol de seus objetivos. 
Entretanto, o processo de se perceber educador é complexo, cheio de tensões. Nosso sujeito se apresenta, então, um docente que vive em meio a essas tensões: a tensão da contrahegemonia - acreditar em uma educação que vai além da simples transmissão de conteúdo (currículo tradicional/mecanicista), mas que permeia diversas dimensões do aluno como Ser Humano, como um Ser dialógico que se constitui coletivamente; a tensão de sua identidade híbrida (hibridismo como forma de conhecimento) - um professor que vive na fronteira em sala de aula.

\section{Referências}

AMORIM, M. Cronotopo e exotopia. In: BRAIT, B. (Org.). Bakhtin: outros conceitoschave. São Paulo: Contexto, 2006. p. 95-114.

. O pesquisador e seu outro: Bakhtin nas ciências humanas. São Paulo: Musa, 2004.

BAKHTIN, M. Estética da criação verbal. 3. ed. São Paulo: Martins Fontes, 2011.

. Marxismo e filosofia da linguagem. 12. ed. São Paulo: Hucitec, 2006.

. Para uma filosofia do ato responsável. [São Carlos]: Pedro \& João, 2010.

BRAIT, B. Análise e teoria do discurso In: . (Org). Bakhtin: outros conceitos-chave. São Paulo: Contexto, 2006. p. 9-31.

- (Org.). Bakhtin: dialogismo e construção do sentido. 2. ed. Campinas: Editora da UNICAMP, 2005.

CLARK, K.; HOLQUIST, M. Mikhail Bakhtin. São Paulo: Perspectiva, 1998.

FARACO, C. A. Linguagem \& diálogo: as idéias lingüísticas do círculo de Bakhtin. São Paulo: Parábola Editorial, 2009.

. Um posfácio meio impertinente. In: BAKHTIN, M. Para uma filosofia do ato responsável. [São Carlos]: Pedro \& João, 2010. p. 147-158.

FREIRE, P. Pedagogia da autonomia: saberes necessários à prática educativa. Rio de Janeiro: Paz e Terra, 1996.

GIROUX, H. Os professores como intelectuais: rumo a uma pedagogia crítica da aprendizagem. Porto Alegre: Artes Médicas, 1997.

GOULART, C. Processos escolares de ensino e aprendizagem, argumentação e linguagens sociais. Bakhtiniana, São Paulo, v. 1, n. 4, p. 50-62, 2010. Disponível em: <http://revistas. pucsp.br/index.php/bakhtiniana/article/view/4298/2902>. Acesso em: 12 ago. 2015. 
PONZIO, A. A concepção bakhtiniana do ato como dar um passo. In: BAKHTIN, M. Para uma filosofia do ato responsável. [São Carlos]: Pedro \& João, 2010. p. 9-38.

RIO DE JANEIRO (Estado). Secretaria de Estado de Educação. Currículo mínimo. [2012]. Disponível em: <http://www.rj.gov.br/web/seeduc/ exibeconteudo?article-id=759820>. Acesso em: 03 jun. 2013.

SAMPAIO, M. C. H. A propósito de Para uma filosofia do ato (Bakhtin) e a pesquisa científica nas ciências humanas. Bakhtiniana, São Paulo, v. 1, n. 1, p. 42-56, 2009.

SOBRAL, A. O ato "responsível", ou ato ético, em Bakhtin, e a centralidade do agente. Signum, Londrina, n. 11/1, p. 219-235, jul. 2008.

Ato/atividade e evento. In: BRAIT, B. (Org). Bakhtin: conceitos-chave. 2. ed. São Paulo: Contexto, 2005. p. 11-36.

O conceito de ato ético de Bakhtin e a responsabilidade moral do sujeito.

BIO\&THIKOS, São Paulo, v. 3, n. 1, p. 121-126, 2009.

SOUZA, S. J. Infância e linguagem: Bakhtin, Vygotsky e Benjamin. 6. ed. Campinas: Papirus, 2001.

TARDIF, M. Saberes docentes e formação profissional. 2. ed. Petrópolis: Vozes, 2002.

TARDIF, M.; LESSARD, C. O trabalho docente: elementos para uma teoria da docência como profissão de interações humanas. Petrópolis: Vozes, 2005.

TEIXEIRA, M. O outro no um: reflexões em torno da concepção bakhtiniana de sujeito. In: FARACO, C. A.; TEZZA, C.; CASTRO, G. (Org.). Vinte ensaios sobre Mikhail Bakhtin. Petrópolis: Vozes, 2006. p. 227-234.

TEZZA, C. Entre a prosa e a poesia: Bakhtin e o formalismo russo. Rio de Janeiro: Rocco, 2003.

TÔRRES, J. J. M. Teoria da complexidade: uma nova visão de mundo para a estratégia.

In: ENCONTRO BRASILEIRO DE ESTUDOS DA COMPLEXIDADE, 1., 2005,

Curitiba. Anais... Curitiba: PUCPR, 2005. p. 1-10. Disponível em: < http://wp.ufpel.edu.br/ consagro/files/2010/09/TORRES-Teoria-Da-Complexidade-e-Estrategia.pdf>. Acesso em: 12 ago. 2015.

YOUNG, M. F. D. O futuro da educação em uma sociedade do conhecimento: o argumento radical em defesa de um currículo centrado em disciplinas. Revista Brasileira de

Educação, Rio de Janeiro, v. 16, n. 48, p. 609-623, 2011. 